\title{
Stensen's duct sialolith in a geriatric patient
}

\author{
Department of Dentistry, Government Taluk Head Quarters Hospital, Malappuram, India
}

Thorakkal Shamim and Prabha Surendran Renjini

\section{LETTERS TO EDITOR}

Sialolithiasis is a common salivary gland disorder causing obstructive disease with only $5-20 \%$ of cases reported in the parotid gland [1]. The incidence of sialolithiasis is more common in males than in females and children and it is less in parotid gland due to reduced salivary viscosity, higher protein levels, and the downward course of the Stensen's duct [1].

This letter adds another case of Stensen's duct sialolith, which occurred in a 68-year-old Indian man who presented to the dental department with a 1-year history of pain and swelling in the right cheek.

There was no relevant medical history of renal disease or any other systemic disease that may alter salivary function, which creates a predisposition to sialolith formation. The symptoms started as waxing and waning episodes of swelling and discomfort, and later as persistent pain and swelling. There was difficulty in mastication and pain was usually aggravated during mealtimes.

Intraoral examination revealed a $0.75 \times 0.75 \mathrm{~cm}$ stony hard mass on the right side of the buccal mucosa (Fig. 1A), suggestive of obstruction of the Stensen's duct of the parotid gland. On milking the duct, pus was seen extruding from the duct and the patient was put on conservative therapy using oral analgesia, hydration therapy, local warm heat therapy, and antibiotics.

The X-ray of the right cheek revealed a radiopaque substance in the region of the right Stensen's duct. After infection subsided, an $8 \mathrm{~mm}$ sized sialolith was surgically removed under local anesthesia (Fig. $1 \mathrm{~B}$ and $\mathrm{IC}$ ). One year after treatment, he remained free of disease.
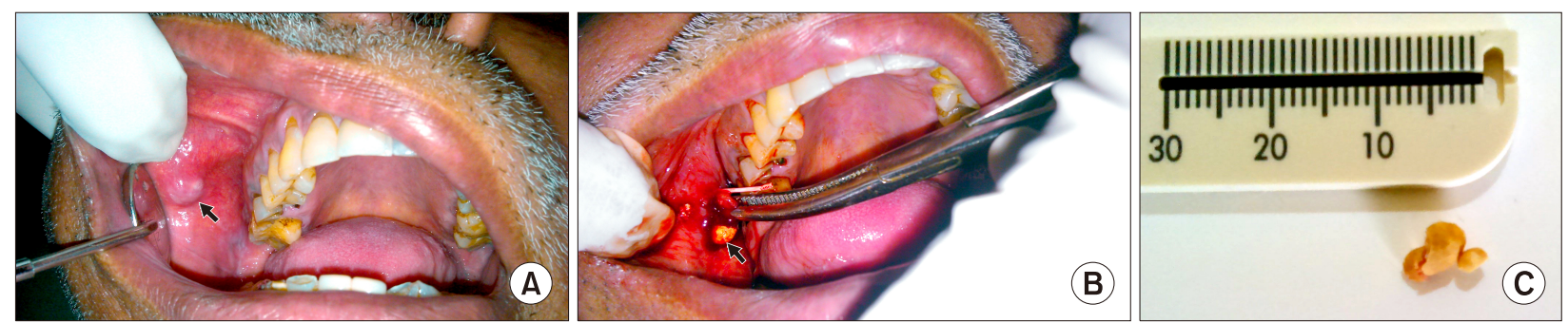

Fig. 1. Stensen's duct sialolith. (A) $0.75 \times 0.75 \mathrm{~cm}$ stony hard mass on the right side of the buccal mucosa. (B) Surgical exploration of sialolith under local anesthesia. (C) Removed sialolith. Gross photograph of sialolith.

Received November 22, 2017. Revised November 22, 2017. Accepted November 29, 2017.

Correspondence to: Thorakkal Shamim

Department of Dentistry, Government Taluk Head Quarters Hospital, Shangrila, Parappanangadi, Malappuram 676303, India Tel: +91-989-5447351, E-mail: shamu3duad@gmail.com

(a) This is an open-access article distributed under the terms of the Creative Commons Attribution Non-Commercial License (http:// creativecommons.org/licenses/by-nc/4.0/), which permits unrestricted non-commercial use, distribution, and reproduction in any medium, provided the original work is properly cited.

Copyright (c) The Korean Pain Society, 2018 
In the present reported case of sialolithiasis, the diagnosis was delayed for 1 year since the pain started as waxing and waning episodes and ended as acute pain. The diagnosis of sialolithiasis was made by ultrasonography since it was readily available, highly specific, and a noninvasive and cost-effective procedure in the above case [2]. Ultrasonography-guided minimally invasive removal of $\mathrm{pa}^{-}$ rotid calculi has already been reported in the literature from India [2].

Therefore, the clinician (either dental or medical) should take utmost care to rule out a history of sialolithiasis, i.e., it should be anticipated that the disease pathogenesis, in this case for one year, may have proceeded in the following sequence: sialadenitis, salivary duct dilatation, and abscess due to sialolith.

\section{CONFLICTS OF INTEREST}

The authors declare that there is no conflicts of interest and no source of funding.

\section{REFERENCES}

1. Arunkumar KV, Garg N, Kumar V. Oversized submandibular gland sialolith: a report of two cases. J Maxillofac Oral Surg 2015; 14 Suppl 1: 116-9.

2. Patnaik U, Nair S, Mishra A. Ultrasonography-guided minimally invasive removal of parotid calculi: a prudent approach. Ear Nose Throat J 2016; 95: 78-80. 